\title{
Effect of Calcium on the Physical Properties of Stirred Probiotic Yogurt
}

\author{
L. Ramasubramanian, ${ }^{*}$ C. Restuccia, $†$ and H. C. Deeth ${ }^{* 1}$ \\ *School of Land, Crop and Food Sciences, University of Queensland, Brisbane, 4072, Australia \\ †Parmalat Australia, South Brisbane, 4101, Australia
}

\section{ABSTRACT}

The effect of calcium on the viscosity, firmness, and smoothness, as determined by extent of nodulation, of stirred probiotic yogurt produced by bacterial fermentation was investigated. Standardized milk for yogurt manufacture was prepared, and calcium was added or removed from the system. Calcium was added as $\mathrm{Ca}^{2+}$ in the form of $\mathrm{CaCl}_{2}$ (up to $13.6 \mathrm{mM}$ ) or nonionic calcium as Gadocal-K (calcium potassium citrate; up to $49.8 \mathrm{mM}$ ). Calcium was removed by chelating with sodium citrate (up to $16 \mathrm{mM}$ ) or by cation exchange with Amberlite IR-120 plus (sodium form) resin (up to $10 \mathrm{~g} / \mathrm{L}$ ). Calcium chloride and sodium citrate were added either before or after heat treatment of milk, and nonionic calcium was added before heat treatment. Calcium removal by ion exchange was performed before heat treatment. Neither $\mathrm{Ca}^{2+}$ addition nor removal by chelation with citrate resulted in stirred yogurt with viscosity, firmness, and smoothness superior to those of the control yogurt, whereas addition of 49.8 $\mathrm{m} M$ nonionic calcium and removal of calcium $(5.6 \mathrm{~m} M$ or $\sim 10 \%$ of total calcium) by cation exchange improved the firmness and viscosity without affecting yogurt smoothness. The study identified Gadocal-K as a possible source of calcium fortification of stirred yogurt without loss of texture.

Key words: calcium, stirred yogurt, nodulation, viscosity

\section{INTRODUCTION}

Yogurt is a product resulting from fermentation of milk by a mixed starter culture, typically of Streptococcus thermophilus and Lactobacillus delbrueckii ssp. bulgaricus (Tamime and Deeth, 1980). Commercial yogurts are classified as either set or stirred according to the method of production and the physical structure of coagulum. Stirred yogurt is made by fermenting milk and stirring the set curd to break the rigid gel struc-

Received May 12, 2008.

Accepted June 24, 2008.

${ }^{1}$ Corresponding author: h.deeth@uq.edu.au ture to obtain a viscous liquid. Physical attributes such as firmness of the coagulum, viscosity, and smoothness of the texture largely determine the consumer appeal of stirred yogurt.

The yogurt gel structure is a network of the milk proteins, caseins, and whey proteins formed during acid gelation. The gel formation is driven by changes in the calcium equilibrium in the milk and resulting hydrophobic interactions between the milk proteins (Lucey and Singh, 1998; Lucey, 2002). In yogurt manufacture, heat treatment of milk causes denaturation of the whey proteins B-lactoglobulin and a-lactalbumin and subsequent protein-protein interactions via disulfide bonding to produce whey protein complexes and whey protein-casein complexes.

Changes in the calcium system of milk are induced by the acidification that results in solubilization of colloidal calcium phosphate (CCP) in the micelles and leads to loss of internal rigidity of the micellar framework and subsequent aggregation of the micelles to form a gel network (Lucey and Singh, 1998). Thus, the calcium content of milk and its distribution in the milk system play a major role in the acid gelation process.

Calcium in milk exists in soluble $(\sim 10 \mathrm{mM})$ and colloidal $(\sim 20 \mathrm{mM})$ forms with some $(\sim 2 \mathrm{mM})$ of the soluble fraction being ionic (Walstra and Jenness, 1984; Fox and McSweeney, 1998; Gaucheron, 2005). The distribution of these calcium forms has a major influence on the structural stability and functionality of the milk proteins. Heat treatment of milk, changes in $\mathrm{pH}$, and addition of calcium salts and chelating agents alter the distribution of calcium and thereby affect the stability of the casein system during milk processing (Umeda and Aoki, 2002; Tsioulpas et al., 2007). Removal of colloidal calcium by dialysis or acidification results in changes in micelle structure, whereas the addition of calcium salts decreases hydration of casein micelles and increases micellar density (Umeda and Aoki, 2002; Ozcan-Yilsay et al., 2007). Calcium removal by ion exchange decreases the $\mathrm{Ca}^{2+}$, resulting in a corresponding reduction in total calcium content of milk and micellar disintegration after removal of more than $50 \%$ of the total calcium (Ranjith et al., 1999). Low $\mathrm{pH}$ and the presence of calcium ions enhance the heat denatur- 
ation of B-lactoglobulin and its preferential attachment to the casein micelle surface during heat treatment of milk (Simons et al., 2002; Vasbinder and de Kruif, 2003).

Decreasing the level of colloidal calcium by addition of small amounts of sodium citrate $(<10 \mathrm{mM})$ has been reported to improve viscosity and gel strength of set yogurt, whereas large additions of citrate resulted in marked reduction of these parameters (Ozcan-Yilsay et al., 2007). A compositional study of milk powders and their effect on yogurt properties has shown that high levels of inorganic phosphate decreased the gel strength of set yogurt by binding divalent calcium ions of the milk (Cheng et al., 2002).

The smoothness of stirred yogurts is an important property for consumer appeal. The occurrence of indispersible particles in an otherwise smooth coagulum, known as nodulation, graininess, lumpiness, grittiness, or sandiness, causes a lack of smoothness of stirred yogurt (Cooper et al., 1974; Robinson, 1981). According to Robinson (1981), nodules are dense aggregates of protein with attached calcium salts and fat. Seasonal variation in the occurrence of nodulation has been reported with the greatest levels in winter months (Cooper et al., 1974); interestingly, the calcium content of milk was also reported to be greatest in winter months (Keogh et al., 1982). The use of calcium caseinate and whey protein concentrate blend as a substitute for milk powder in yogurt mix has been shown to increase nodulation (Remeuf et al., 2003), whereas technological parameters such as $\mathrm{pH}$ and fermentation time and temperature may affect the extent of nodulation in stirred yogurt (Robinson, 1981). Although the exact mechanism of nodule formation is not known, the nodules appear to be the result of protein interactions during yogurt gel formation. Thus, from the knowledge of the chemistry of milk protein-calcium interactions and nodulation in stirred yogurt, the calcium concentration of milk could be expected to be a significant factor determining the extent of nodulation in stirred yogurt.

Studies involving calcium addition to and removal from yogurts are limited. Research on the smoothness of yogurt has focused on the effects of processing parameters and has not addressed the possible role of calcium in acid gelation and the formation of nodules. The purpose of this study was to determine the effect of calcium on the viscosity, firmness, and the extent of nodulation of stirred probiotic yogurt. The study also aimed to determine the effects on these properties of increasing total calcium with or without increasing $\mathrm{Ca}^{2+}$ (by adding ionic or nonionic forms of calcium), decreasing $\mathrm{Ca}^{2+}$ with or without decreasing total calcium (by chelation or ion exchange), and increasing or decreasing calcium at different stages (before and after heat treatment of milk).

\section{MATERIALS AND METHODS}

\section{Ingredients}

Whole milk, skim milk, low-heat skim milk powder, gelatin, inulin, and white sugar were supplied by Parmalat Australia Ltd., South Brisbane, Australia; bacterial cultures ABT5 (Lactobacillus acidophilus, La-5; Bifidobacterium animalis ssp. lactis, BB-12; and Streptococcus thermophilus-5, ST-5) and LGG (Lactobacillus rhamnosus) were obtained from Chr. Hansen Ltd., Hørsholm, Denmark, and Valio Ltd., Vantaa, Finland, respectively. Calcium chloride, sodium citrate, and Amberlite IR-120 plus (sodium form) were obtained from Sigma-Aldrich Ltd., Castle Hill, Australia. Gadocal-K was supplied by Gadot Biochemical Industries Ltd., Haifa Bay, Israel.

\section{Preparation of Milk Samples}

Standardized milk for yogurt manufacture with $\sim 14 \%$ nonfat milk solids and $1.5 \%$ fat was prepared by combining whole milk, skim milk, low-heat skim milk powder, gelatin, inulin, and white sugar. In separate experiments, $\mathrm{Ca}^{2+}$ was added in the form of $10 \%$ solutions of $\mathrm{CaCl}_{2}$ dihydrate, and nonionic calcium was added in the form of a soluble calcium salt, Gadocal-K, calcium potassium citrate containing $15 \%$ calcium. The level of calcium, total or ionic, or both, was decreased by chelating with trisodium citrate dihydrate or by cation exchange with the ion exchange resin, Amberlite IR120 plus (sodium form). Calcium chloride was added to milk either after heat treatment at 1.7, 3.4, 6.8, and $13.6 \mathrm{~m} M$ or before heat treatment at $1,1.7$, and 2.37 $\mathrm{m} M$. Sodium citrate was added at 2, 4, 8, and $16 \mathrm{mM}$ after heat treatment and 2, 4, and $8 \mathrm{~m} M$ before heat treatment. Nonionic calcium was added at 6.2, 12.4, 24.9 , and $49.8 \mathrm{~m} M$ before heat treatment. Calcium removal by ion exchange was accomplished before heat treatment by adding Amberlite IR-120 plus (5, 8, and $10 \mathrm{~g} / \mathrm{L}$ ) to milk, stirring continuously for $20 \mathrm{~min}$, and filtering the milk to remove the resin. After the addition or removal of calcium, milk was vigorously stirred with a laboratory high-speed mixer (model L2R, Silverson Machines Inc., Chesham, Bucks, UK) and heated at $92^{\circ} \mathrm{C}$ for $7 \mathrm{~min}$. These heating conditions are near the midpoint of the optimal range of 90 to $95^{\circ} \mathrm{C}$ for 5 to 10 min recommended by Robinson (2003). The milk was cooled rapidly to $4^{\circ} \mathrm{C}$ and stored at this temperature for $24 \mathrm{~h}$ before fermentation. 


\section{Chemical Analyses}

Total Calcium and $\mathbf{C a}^{2+}$. Total calcium was determined by the EDTA titration method of White and Davies (1958) using calmagite as indicator. The calcium ion concentration of milk samples was measured $24 \mathrm{~h}$ after addition and removal of calcium ions, using a calcium ion selective electrode (TPS Pty. Ltd., Brisbane, Australia). The $\mathrm{Ca}^{2+}$ concentration was calculated from a standard curve obtained using aqueous $\mathrm{CaCl}_{2}$ solutions (Lin et al., 2006). Calibration and measurement of calcium ion concentrations were performed at room temperature $\left(\sim 22^{\circ} \mathrm{C}\right)$.

\section{Fermentation}

Milk was fermented using $0.0025 \%$ bacterial mixed starter culture, ABT5 and 0.0025\% LGG. Milk was warmed to $42^{\circ} \mathrm{C}$ in a water bath, inoculated with starter culture, and stirred briefly to distribute the culture evenly. The milk sample was incubated at a constant temperature of $42^{\circ} \mathrm{C}$ in the water bath for 4 to $5 \mathrm{~h}$ until a $\mathrm{pH}$ of 4.55 was reached. The probiotic yogurt thus obtained was cooled rapidly to room temperature in an iced water bath, stirred (IKA model RW 20.n, SigmaAldrich Ltd.) at $360 \mathrm{rpm}$ for $2 \mathrm{~min}$, filled into sterile containers, and stored at $4^{\circ} \mathrm{C}$ until analyzed.

\section{Evaluation of Physical Properties}

Smoothness. Nodules present in yogurt were enumerated by image analysis (Remeuf et al., 2003). They were isolated from $1 \mathrm{~g}$ of yogurt by repeated rinsing of the yogurt with distilled water. The image of nodules was captured by a digital camera (Samsung Digimax i50, Samsung Ltd., Homebush Bay, Australia) equipped with optical zoom. The image was then used to enumerate nodules using the Image- Pro Plus analysis software (Media Cybernetics Ltd., Bethesda, MD). Nodules with diameters greater than $0.5 \mathrm{~mm}$ were enumerated, and results were expressed in terms of number of nodules per gram of yogurt.

Apparent Viscosity. The apparent viscosity of the stirred yogurt was measured with a Brookfield digital rotational viscometer (model DV-II+, Brookfield Engineering Laboratories Inc., Middleboro, MA) using a spindle 5 at $10 \mathrm{rpm}$ in $150 \mathrm{~mL}$ of yogurt. The spindle was allowed to rotate in the sample for $1 \mathrm{~min}$ at $10^{\circ} \mathrm{C}$. The apparent viscosity reading in centipoise was noted from the digital output of the viscometer. The measurements were performed on duplicate samples.

Firmness. The firmness of the stirred yogurt coagulum was measured by a texture analyzer (model TAXT2, Stable Microsystems, Surrey, UK). The instru- ment was calibrated for a load of $5 \mathrm{~kg}$, and a measuring probe of $3.5 \mathrm{~cm}$ diameter $\times 2 \mathrm{~cm}$ high was used. Firmness was measured as the force of compression when the probe traveled a distance of $2 \mathrm{~cm}$ into the yogurt sample at a speed of $0.2 \mathrm{~mm} / \mathrm{s}$. Samples were analyzed in duplicate.

Statistical Analysis. The work was divided into 4 parts, namely addition of $\mathrm{CaCl}_{2}$ or sodium citrate before heat treatment, addition of $\mathrm{CaCl}_{2}$ or sodium citrate after heat treatment, addition of nonionic calcium (Gadocal-K), and removal of calcium by ion exchange. Each experiment was performed 3 times and independently of the others. The results were analyzed by ANOVA using the Minitab15 statistical software package (Minitab Inc., Chicago, IL). A general linear model Dunnett's test was performed to compare the results of the treatments with those of the control. The test was conducted at a $95 \%$ confidence level, and a $P$-value of $<0.05$ was considered to be significant.

\section{RESULTS AND DISCUSSION}

\section{$\mathrm{Ca}^{2+}$ Concentration and $\mathrm{pH}$ of Yogurt Milk}

The $\mathrm{Ca}^{2+}$ concentration in the milk samples was measured after $24 \mathrm{~h}$ of cold storage after ion addition. The 24-h storage between ion addition and measurement of $\mathrm{Ca}^{2+}$ concentration was adopted for 3 reasons: 1) the equilibrium of calcium in milk is highly buffered, so any addition of calcium ions, chelation of calcium ions with citrate, or removal of calcium by ion exchange redistributes the calcium between the ionic, soluble, and micellar forms (Fox and McSweeney, 1998); the resultant $\mathrm{Ca}^{2+}$ concentration measured after $24 \mathrm{~h}$ is hence more accurate than that measured immediately after addition; 2) heating of milk at about $90^{\circ} \mathrm{C}$ leads to a decrease in $\mathrm{Ca}^{2+}$ concentration of milk caused by the transfer of soluble calcium to the colloidal phase, and this loss is largely reversible to close to the initial value during overnight storage at $4^{\circ} \mathrm{C}$ (Geerts et al., 1983); and 3 ) in an ideal industrial situation, it is desirable to leave the heat-treated milk in cold storage overnight to allow complete rehydration of the milk powder (Robinson, 1981). Therefore, measuring the $\mathrm{Ca}^{2+}$ concentration in milk just before fermentation provides the most accurate estimate of the active $\mathrm{Ca}^{2+}$ in the milk involved in the acid coagulation process.

Average $\mathrm{Ca}^{2+}$ levels of $1.09,1.34$, and $1.18 \mathrm{~m} M$ were measured for control milk samples in the experiments (Figure 1). These values differ, because different batches of milk were used for the different replicate experiments. The $\mathrm{Ca}^{2+}$ concentration of milk is reported to be 1 to $3 \mathrm{~m} M$ and to differ with the method of measurement (White and Davies, 1958; Gaucheron, 2005; Lin et al., 
a)
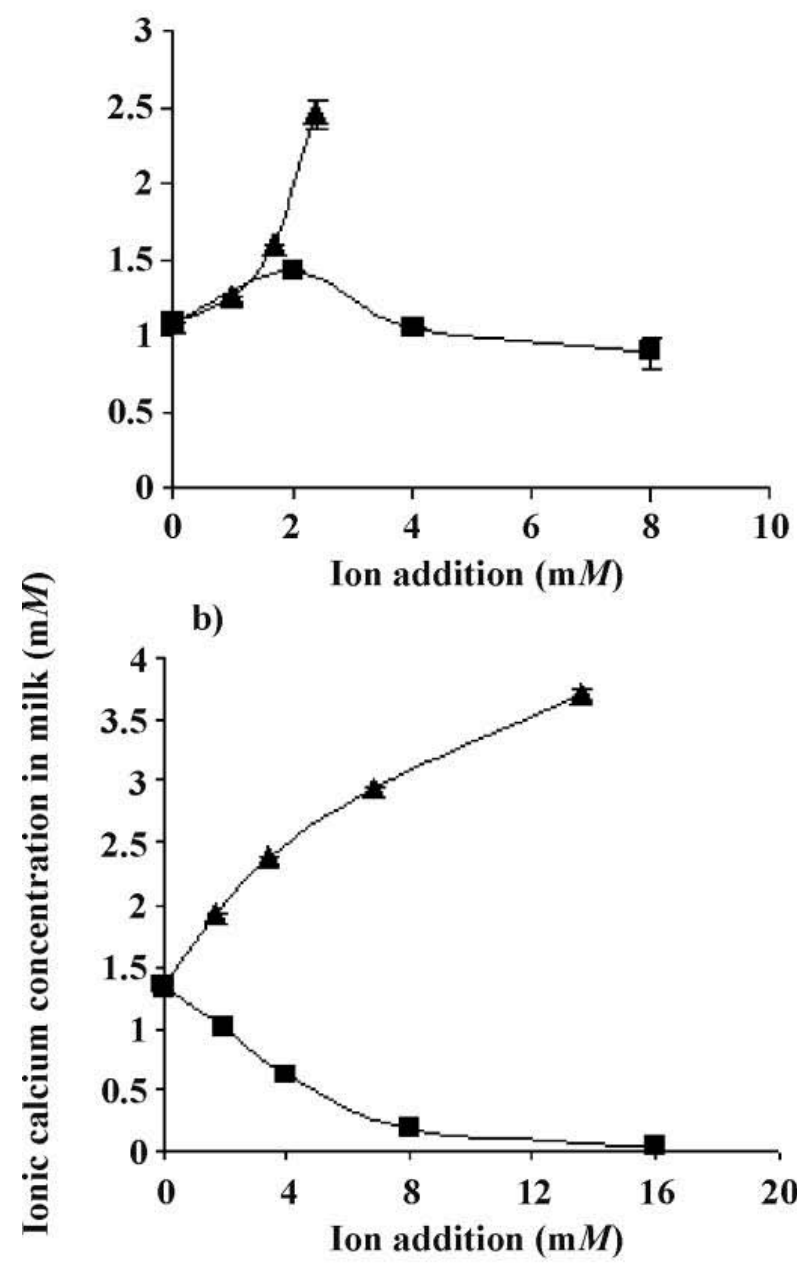

c)

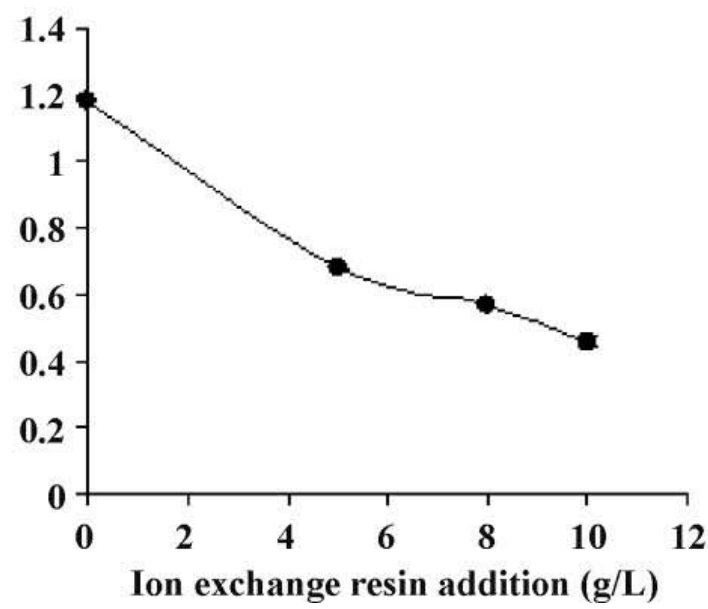

Figure 1. Calcium ion concentration of milk samples as a function of added ionic calcium $(\boldsymbol{\Delta})$, citrate $(\boldsymbol{\bullet})$, and ion exchange resin, Amberlite IR-120 plus, Sigma-Aldrich Ltd., Castle Hill, Australia (•): a) calcium and citrate added before heat treatment of milk, b) calcium and citrate added after heat treatment of milk, c) ion exchange resin added before heat treatment of milk. Data points represent averages of 3 experiments.
2006). Therefore, the use of the ion selective electrode method in the present study may have influenced the absolute values of $\mathrm{Ca}^{2+}$ concentration obtained.

Addition of calcium in the form of $\mathrm{CaCl}_{2}$ and removal by chelation with sodium citrate resulted in changes in $\mathrm{Ca}^{2+}$ concentration of milk as shown in Figure 1. The $\mathrm{Ca}^{2+}$ concentration increased steadily when calcium ions were added before or after heat treatment of milk. It was not possible to add calcium ions in concentrations greater than $2.37 \mathrm{~m} M$ before heat treatment, because such concentrations cause instability of milk during heat treatment (Augustin and Clarke, 1990; Hansen and Fligner, 1995). Addition of the nonionic calcium salt Gadocal-K did not change the $\mathrm{Ca}^{2+}$ concentration. Removal of calcium by citrate chelation resulted in a significant decrease in $\mathrm{Ca}^{2+}$ when citrate was added after heat treatment but did not change $\mathrm{Ca}^{2+}$ significantly when added before heat treatment. The removal of calcium with ion exchange resin caused a decrease of $\mathrm{Ca}^{2+}$ of up to $62 \%$ (to $0.46 \mathrm{mM}$; Figure 1c). The reductions in total calcium for additions of 5,8 , and $10 \mathrm{~g} / \mathrm{L}$ of resin were $5.6,7.2$, and $11.9 \mathrm{mM}$ or 10,13 , and $21 \%$, respectively. Thus, even though the calcium is removed by ion exchange as $\mathrm{Ca}^{2+}$, the equilibrium continues to reestablish by converting nonionic calcium to $\mathrm{Ca}^{2+}$.

A slight translucency was observed in the milk samples with $8 \mathrm{~m} M$ citrate addition before heat treatment, 8 and $16 \mathrm{~m} M$ citrate after heat treatment, and with calcium removal (11.9 $\mathrm{m} M$ or $21 \%$ ) using ion exchange $(10 \mathrm{~g} / \mathrm{L})$ indicating partial disintegration of micelles resulting from solubilization of some of the micellar CCP (Johnston and Murphy, 1992). This further illustrates that any removal of $\mathrm{Ca}^{2+}$ results in a transfer of calcium from the micelle to restore the ionic equilibrium and, beyond a threshold of micellar calcium removal, causes disintegration of the micelle and the observed translucency.

Addition of $\mathrm{CaCl}_{2}$ resulted in a decrease in the $\mathrm{pH}$ of milk, whereas removal of calcium ions with citrate or ion exchange increased $\mathrm{pH}$ (Figure 2). These results can be explained by the equilibrium of $\mathrm{Ca}^{2+}$ in milk, which can be expressed by the following equation (Philippe et al., 2003; Lin et al., 2006):

$$
3 \mathrm{Ca}^{2+}+2 \mathrm{HPO}_{4}{ }^{2-} \leftrightarrow \mathrm{Ca}_{3} \mathrm{PO}_{4} \downarrow+2 \mathrm{H}^{+} .
$$

Based on this relationship between the $\mathrm{Ca}^{2+}$ and $\mathrm{pH}$, addition of calcium ions during the experiment would increase the hydrogen ion concentration and decrease the $\mathrm{pH}$ of the milk. On the other hand, removal of calcium ions from the system by citrate or ion exchange with sodium would decrease the hydrogen ion concentration, resulting in an increase in $\mathrm{pH}$. The addition of 
nonionic calcium as Gadocal-K did not change the $\mathrm{pH}$, because it did not change the $\mathrm{Ca}^{2+}$ concentration.

\section{Smoothness of Stirred Yogurt}

Smoothness of the stirred yogurt samples was assessed in terms of the extent of nodulation, a measure of the number of dense aggregates of protein known as nodules present in the stirred yogurt coagulum (Davis, 1973; Cooper et al., 1974). Some studies have considered smoothness as a physical property (Remeuf et al., 2003), whereas others have considered smoothness as a sensory characteristic of yogurt (Martuinez et al., 2002). Considering that the presence of nodules affects the visual appeal of yogurt, it was decided to physically enumerate the number of nodules greater than $0.5 \mathrm{~mm}$ in diameter in $1 \mathrm{~g}$ of stirred yogurt. The fewer the nodules present, the smoother the yogurt.

Addition of $\mathrm{CaCl}_{2}$ to the milk, both before and after heat treatment, resulted in a significant increase in nodulation in the yogurt $(P<0.05$; Table 1 , Figures $3 \mathrm{a}$ and $3 \mathrm{~b})$. The extent of nodulation increased with increasing $\mathrm{Ca}^{2+}$. Addition of 2 and $4 \mathrm{~m} M$ citrate before heat treatment also resulted in a significant increase in the number of nodules $(P<0.05)$; however, when citrate was added after heat treatment, it did not significantly alter the extent of nodulation except at the greatest addition of $16 \mathrm{mM}$ (Table 1, Figures 3a and $3 \mathrm{~b})$. Calcium removal by ion exchange treatment with 8 and $10 \mathrm{~g} / \mathrm{L}$ of resin (removal of 7.2 and $11.9 \mathrm{~m} M$ total calcium, respectively) before heat treatment increased nodulation significantly $(P<0.05)$, but calcium removal $(5.6 \mathrm{mM}$ ) by treatment with $5 \mathrm{~g} / \mathrm{L}$ of resin (removal of $5.6 \mathrm{mM}$ ) did not alter the extent of nodulation (Figure 3d). Addition of nonionic calcium (Gadocal-K) did not significantly increase or decrease the occurrence of nodules in the stirred yogurt (Figure 3c).

A high level of calcium ions in milk clearly magnifies the problem of nodulation in stirred yogurt. A plausible explanation can be advanced for this; however, it is more difficult to explain why reduction of $\mathrm{Ca}^{2+}$ does not have the opposite effect. In fact, reduction of $\mathrm{Ca}^{2+}$ by either citrate or ion exchange either had little effect on nodulation or it significantly increased nodulation.

High calcium ion concentration and low $\mathrm{pH}$ in milk are known to favor denaturation of B-lactoglobulin and its association with the casein micelle (Vasbinder and de Kruif, 2003). Substitution of whey protein concentrate for skim milk powder and a high whey proteinto-casein ratio also enhance nodulation (Remeuf et al., 2003). Lucey and Singh (1998) reported that the presence of large amounts of denatured whey proteins attached to micelle surfaces may increase local stresses during rearrangement of casein micelle particles in a)

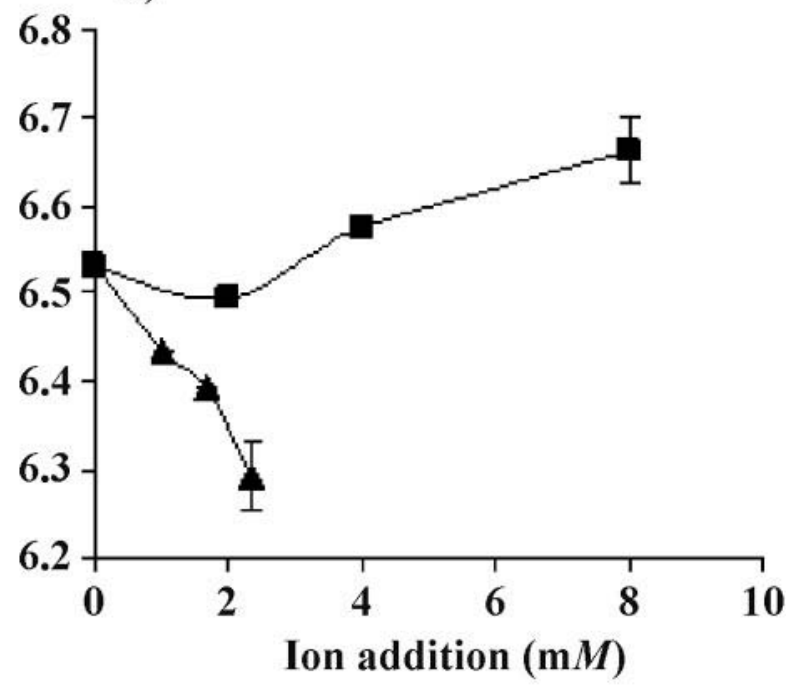

b)

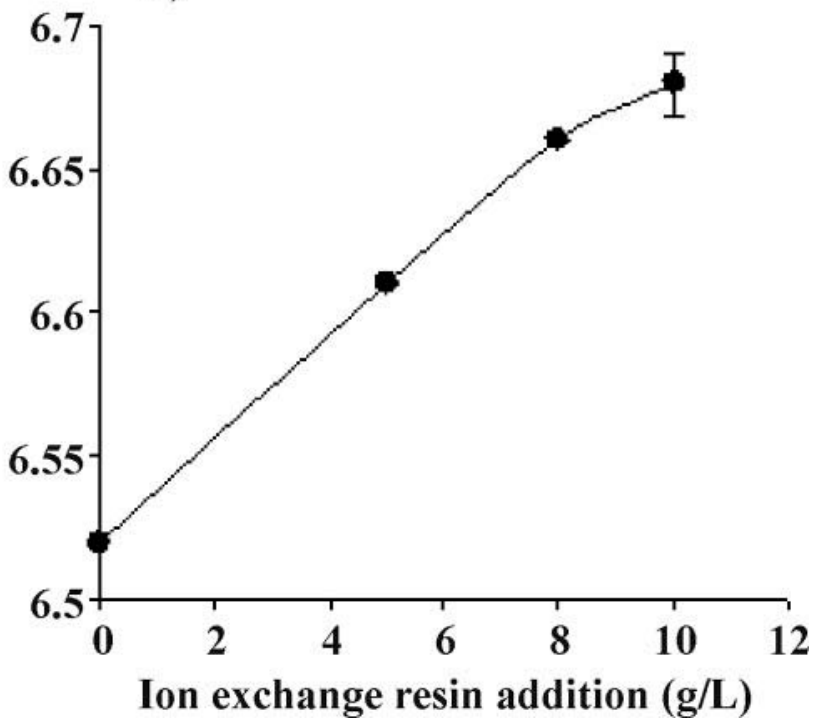

Figure 2. pH of milk samples measured immediately before heat treatment as a function of added ionic calcium ( $\mathbf{\Lambda})$, citrate $(\mathbf{\square})$, and ion exchange resin addition $(\bullet)$ before heat treatment of milk.

the acid coagulation process and lead to fractures in the gel structure, which may lead to development into nodules in the yogurt. Hence, if the added calcium ions and the consequent low $\mathrm{pH}$ enhanced whey protein denaturation during the heat treatment of milk, local stresses in the gel matrix may be increased, leading to increased formation of nodules in the yogurt after stirring. The effect of calcium ion addition could work in combination with the consequent low $\mathrm{pH}$, because both decrease steric repulsion between the casein micelles, contributing to a firmer gel due to intense cross-linking between the micelles. Lee and Lucey (2006) reported 
Table 1. Effect of calcium addition and removal on nodulation, viscosity, and firmness of stirred yogurt ${ }^{1}$

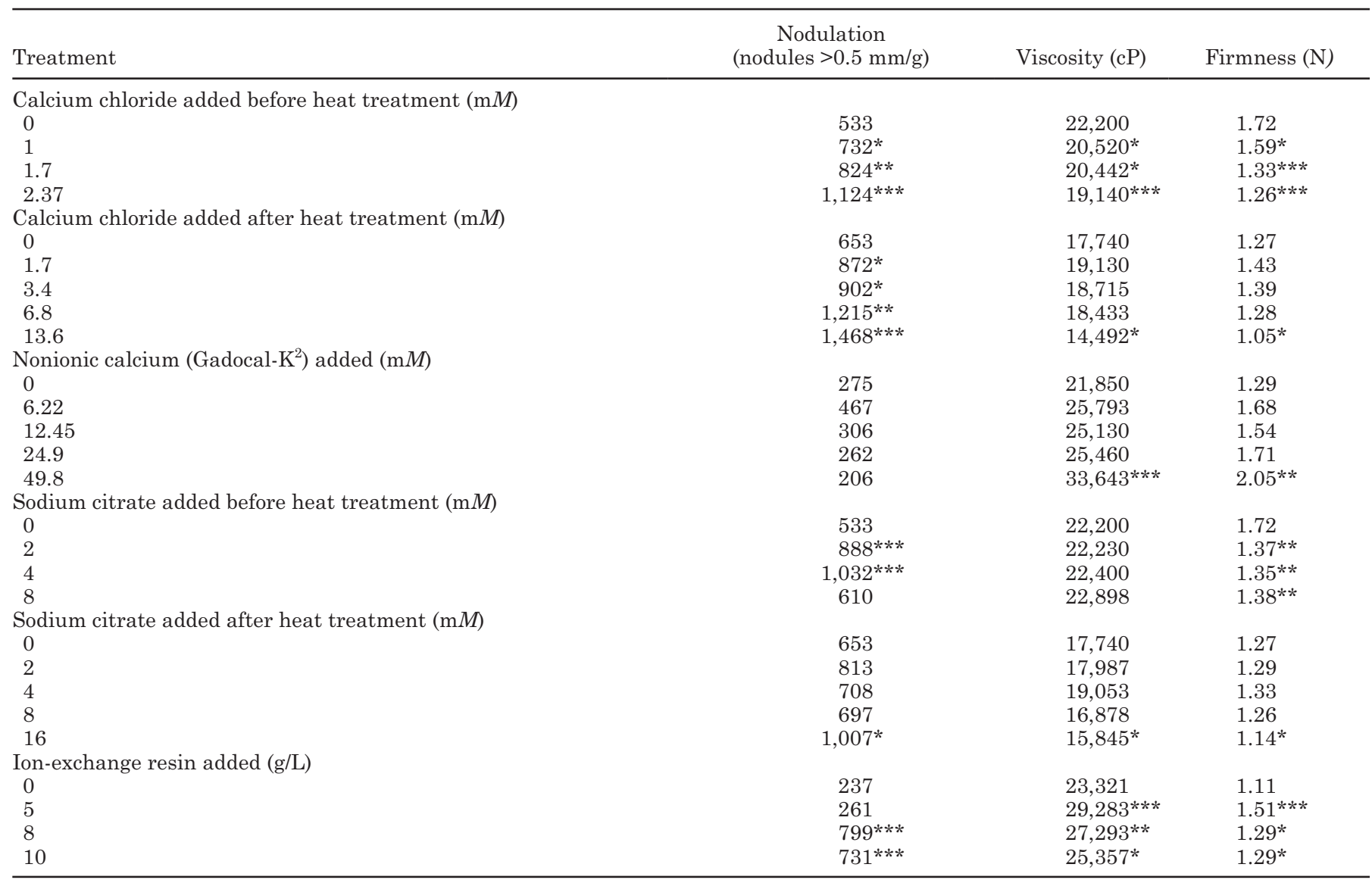

${ }^{1} 0 \mathrm{~m} M$ or $0 \mathrm{~g} / \mathrm{L}$ addition in each treatment represents a control.

${ }^{2}$ Gadot Biochemical Industries Ltd., Haifa Bay, Israel.

*Indicates means are significantly different $(P<0.05)$ from those of control samples; **Indicates means are highly significantly different $(P<$ $0.01)$ from those of control samples; ${ }^{* * *}$ Indicates means are very highly significantly different $(P<0.001)$ from those of control samples.

that set gels with less branching and cross-linking produced stirred yogurts with less dense protein aggregates. Based on this theory, calcium ion addition may give a firmer set yogurt with increased cross-linking, which, when stirred, results in a stirred yogurt with more dense protein aggregates and decreased smoothness.

To explain the significantly increased level of nodulation at high levels of calcium removal by ion exchange resin $(8$ and $10 \mathrm{~g} / \mathrm{L})$ and chelation by citrate $(<8 \mathrm{mM})$, before heat treatment, it is suggested that CCP solubilization occurs to the extent of causing release of weakly bound casein aggregates from the micelle without completely destroying the micelle integrity. Thus, the milk contains some free casein aggregate particles, which are part of the serum rather than the micelles. When this milk is heat-treated, the whey proteins denature and attach to the micelle surfaces. Some of these denatured whey proteins may also attach to the free casein aggregate particles present in the serum. The whey protein-casein aggregates thus formed would not be part of the micelle, and hence, during acid coagulation, while micelles integrate into the gel, these aggregates may fail to participate in the gel network and remain as dense proteinaceous particles within the continuous yogurt coagulum. These small particles would have greater mobility than the micelles in the milk and may undergo excessive rearrangement during the acid coagulation process, thus exerting excessive local stress on the casein micelle network. Considering that such local stress can lead to fractures during formation of the gel network by acid coagulation (Lucey and Singh, 1998) and development of nodules after stirring, these small protein aggregates may contribute to enhanced nodulation. The above hypothesis is supported by the fact that calcium chelation by citrate after heat treatment has much less effect on nodulation than when the calcium was chelated before heat treatment. In the former situation, heat treatment would already have caused formation of whey protein-casein micelle com- 
plexes from which release of casein aggregates would be greatly hindered.

The observed loss in smoothness due to high levels of calcium removal may also be induced by the $\mathrm{pH}$ increase associated with calcium ion removal leading to an altered rate of acid development during the acid coagulation process. Calcium removal by chelation or ion exchange leads to dissolution of micellar calcium phosphate and decreases the amount of free calcium ions available, both of which can indirectly alter the rate of acidification, thereby affecting acid coagulation (Umeda and Aoki, 2002). As nodulation increases with increased rate of acidification and slight changes in the acid coagulation process (Cooper et al., 1974; Robinson, a)

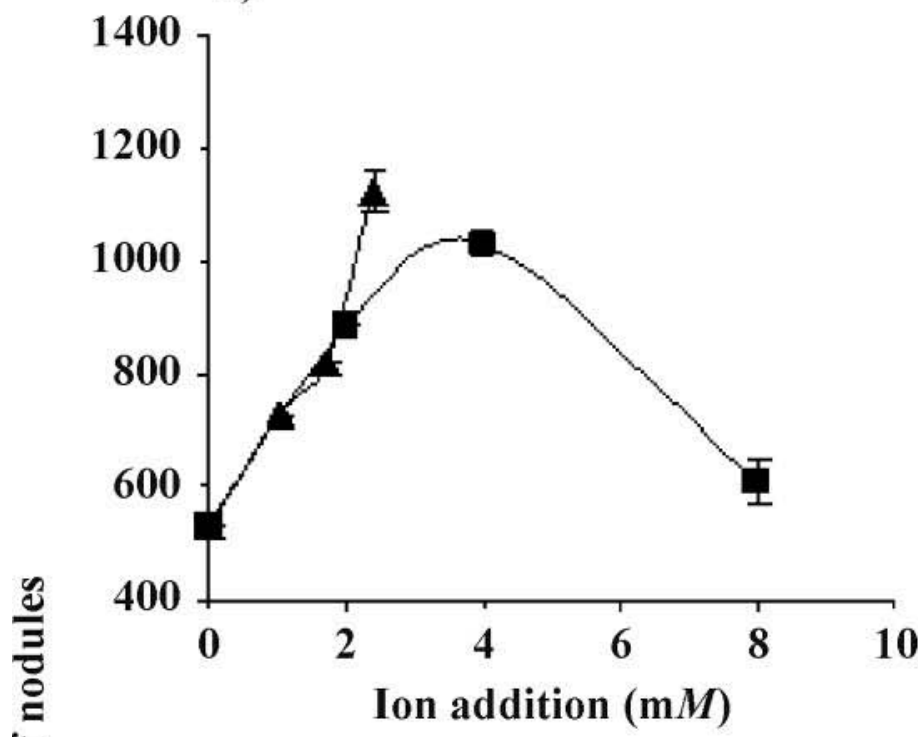

c)

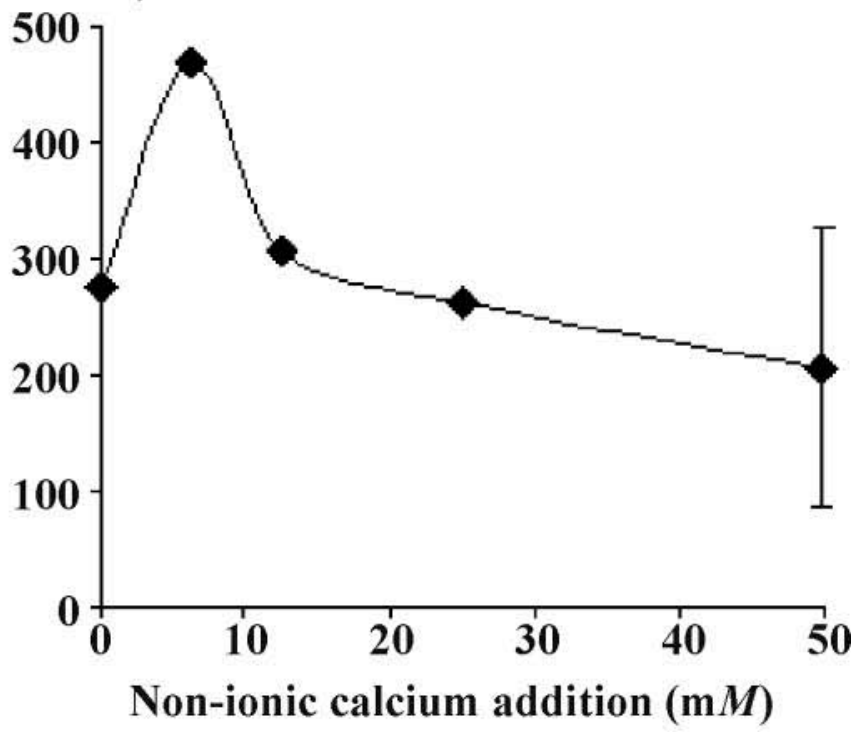

d)

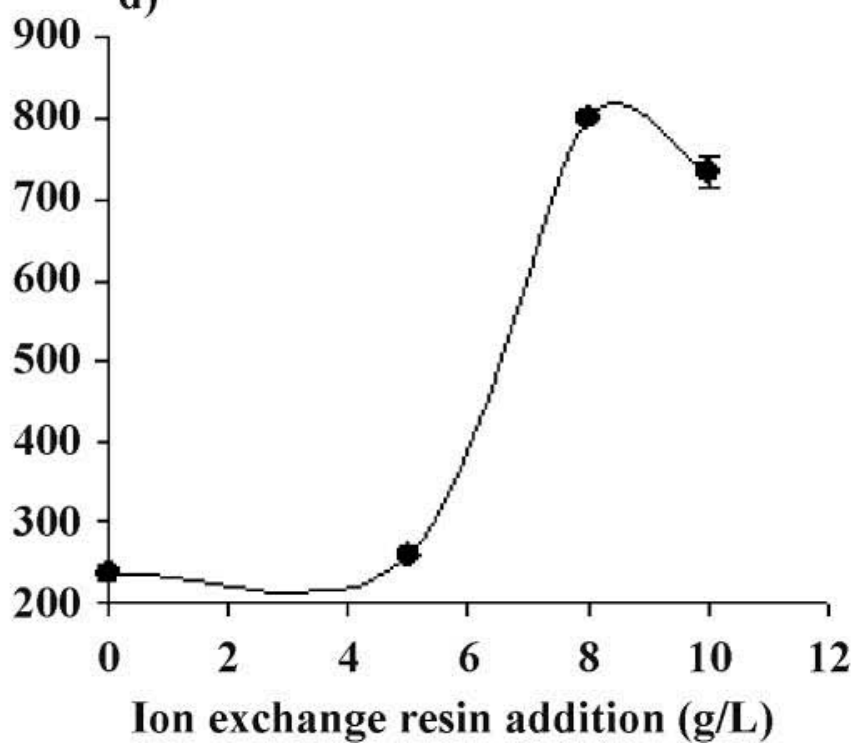

Figure 3. Nodulation in yogurt (nodules greater than $0.5 \mathrm{~mm}$ diameter in $1 \mathrm{~g}$ of yogurt) as a function of added ionic calcium, citrate, non-ionic calcium (Gadocal-K, Gadot Biochemical Industries Ltd., Haifa Bay, Israel), and ion exchange resin (Amberlite IR-120 plus, SigmaAldrich Ltd., Castle Hill, Australia): a) ionic calcium and citrate added before heat treatment, b) ionic calcium and citrate added after heat treatment, c) non-ionic calcium added before heat treatment, d) ion exchange resin added before heat treatment of milk. $\boldsymbol{\Delta}=$ ionic calcium; - = citrate; = non-ionic calcium; $\bullet=$ ion exchange resin. Error bars represent pooled standard error. Data points represent averages of 3 experiments. 
1981), calcium removal may enhance the formation of nodules by altering the acidification process.

Nonionic calcium addition in the form of Gadocal-K did not affect the smoothness of the yogurt. Studies involving $\mathrm{Ca}^{2+}$ addition to milk products have often indicated that the resulting effects such as heat instability of milk, changes in whey protein-casein interactions during the heat treatment of milk, and protein precipitation may be the result of a combination of 2 factors - high calcium ion concentration and low $\mathrm{pH}$ (Hansen and Flinger, 1995; Tsioulpas et al., 2007). Addition of a calcium salt in combination with a chelating or alkaline agent improves the stability of the milk to heat treatment (Hansen and Fligner, 1995). Therefore, it may be beneficial to prevent the $\mathrm{pH}$ decrease (from that of normal milk) associated with calcium addition. Adding calcium by means of Gadocal-K prevents this $\mathrm{pH}$ decrease, thereby preventing enhanced whey protein denaturation and alterations in whey protein-casein attachment during the heat treatment of milk, which can contribute to nodulation. It therefore appears that the use of Gadocal-K as a source of nonionic calcium allows the smoothness of yogurt to be retained by not affecting either $\mathrm{Ca}^{2+}$ concentration or $\mathrm{pH}$.

\section{Firmness and Viscosity of Stirred Yogurt}

The effects of calcium and citrate addition on firmness and viscosity of stirred yogurt are depicted in Figures 4 and 5 , respectively. With the exception of the yogurts made with added citrate before heat treatment (Figures $4 \mathrm{a}$ and 5a), firmness and viscosity showed similar trends. Neither addition of $\mathrm{Ca}^{2+}$ nor citrate improved firmness and viscosity, which are important quality attributes of yogurt. In fact, some treatments, namely addition of $13.6 \mathrm{~m} M$ calcium ions after heat treatment and all levels of calcium ion addition before heat treatment, significantly $(P<0.05)$ decreased the viscosity and firmness of the yogurts (Table 1). Coupled with the fact that addition of $\mathrm{Ca}^{2+}$ or citrate did not improve the smoothness of the yogurt, these treatments do not appear to be beneficial in yogurt manufacture.

The observation that calcium chelation by citrate addition of $16 \mathrm{~m} M$ after heat treatment led to a significant reduction $(P<0.05$; Table 1$)$ in viscosity and firmness of yogurt is consistent with the findings of Ozcan-Yilsay et al. (2007) of a loss in gel strength of set yogurt with the addition of $>10 \mathrm{~m} M$ trisodium citrate after heat treatment of milk. They further observed an improvement in gel strength of yogurt with the addition of $<10 \mathrm{~m} M$ of trisodium citrate. In the present study, however, such a significant improvement in firmness and viscosity for similar citrate additions was not noted.
In contrast to the effect of adding $\mathrm{Ca}^{2+}$, adding a high level $(49.8 \mathrm{~m} M)$ of nonionic calcium resulted in yogurts with significantly $(P<0.05)$ greater firmness and viscosity values than the corresponding control samples (Figure 4c; Table 1). This is an important result, because it was not accompanied by an increase in nodulation (Figure 3c). It is also important nutritionally, because such an addition of calcium, which is equivalent to over $160 \%$ of the total calcium level in milk, could be used for calcium fortification without adversely affecting the properties of the yogurt.

A marked improvement in firmness and viscosity of yogurt was also observed when calcium was removed by ion exchange. Treatment of milk with 5,8 , and 10 $\mathrm{g} / \mathrm{L}$ of resin resulted in a significant increase in firmness $(P<0.05)$, whereas treatment with 5 and $8 \mathrm{~g} / \mathrm{L}$ of resin resulted in significantly greater viscosity $(P<$ 0.05) compared with the control (Table 1). Maximum firmness and viscosity occurred when $5 \mathrm{~g} / \mathrm{L}$ of ion exchange resin was used. This ion exchange treatment caused no increase in nodulation; therefore, removal of a small percentage $(\sim 10 \%)$ of calcium from the yogurt milk could improve the consistency of yogurt without adversely affecting its smoothness.

The observed firmness and viscosity profiles of stirred yogurt are a consequence of the changes in the calcium equilibrium of milk due to calcium addition and removal. The calcium system of milk is highly buffered. In other words, if the concentration of calcium ions in milk is diminished by any treatment, the supply is refurbished from the reserve of nonionic soluble and colloidal forms. Similarly, when the calcium content of milk is increased, this increase is distributed between the ionic and nonionic soluble and colloidal phases (Fox and McSweeney, 1998; Gaucheron, 2005). Addition of $\mathrm{CaCl}_{2}$ to milk results in increased binding of $\mathrm{Ca}^{2+}$ to phosphate ions, whereas the addition of Gadocal-K increases the soluble calcium content; both result in subsequent transfer of calcium to the micellar phase (CCP). Increases in CCP enhance aggregation of casein micelles, thereby giving a rigid acid gel and a stirred yogurt with high viscosity and firmness. On the other hand, addition of citrate ions decreases the free calcium ions in the milk, resulting in solubilization of the CCP from the micelles and loss in rigidity of the micellar framework (Canabady-Rochelle et al., 2007). The resulting acid gel is softer and on stirring produces yogurt with a low viscosity and firmness. Ozcan-Yilsay et al. (2007) observed improved gel properties for yogurts with limited calcium removal and suggested that such an improvement could be due to an indirect effect of CCP solubilization on the rigidity of the micellar framework. In our study, yogurts resulting from milks with calcium removed by ion exchange were firmer 
and more viscous (Table 1, Figures $4 \mathrm{~d}$ and $5 \mathrm{~d}$ ) and may have been characterized by such an effect. Calcium removal and subsequent solubilization of CCP could be expected to result in a weaker gel and a yogurt with poor viscosity and firmness. However, the increase in viscosity and firmness of yogurt with calcium removal by ion exchange suggests that the levels of calcium removal probably did not cause massive micelle disruption. It may have only caused slight changes in the network, leading to an increase in molecular flexibility and thereby enhanced formation of cross-links between the casein particles (Ozcan-Yilsay et al., 2007).
Poor viscosity and firmness, and grittiness, have been reported with calcium fortification of yogurt in the form of organic salts; however, smooth texture and high viscosity have been obtained with the addition of calcium salts in combination with chelating agents such as citrate with $\mathrm{pH}$ adjustment to the natural $\mathrm{pH}$ of milk (6.7; Hansen and Fligner, 1995). In the present study, addition of $49.8 \mathrm{~m} M$ nonionic calcium (in the form of Gadocal-K) without any $\mathrm{pH}$ adjustment produced yogurt with a greater viscosity and firmness compared with yogurt made without added nonionic calcium. Addition of Gadocal-K did not change the $\mathrm{pH}$ of the milk

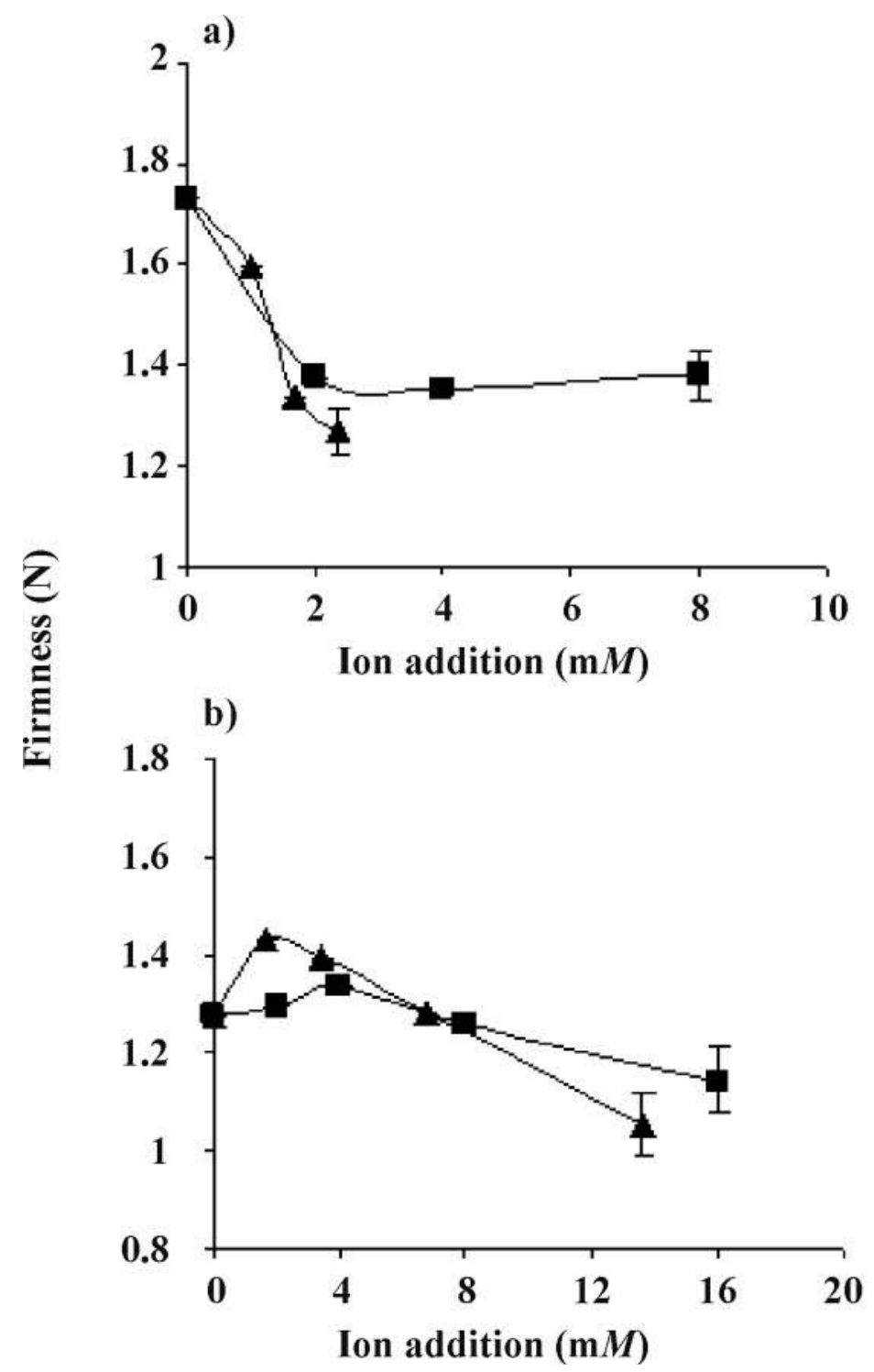

c)

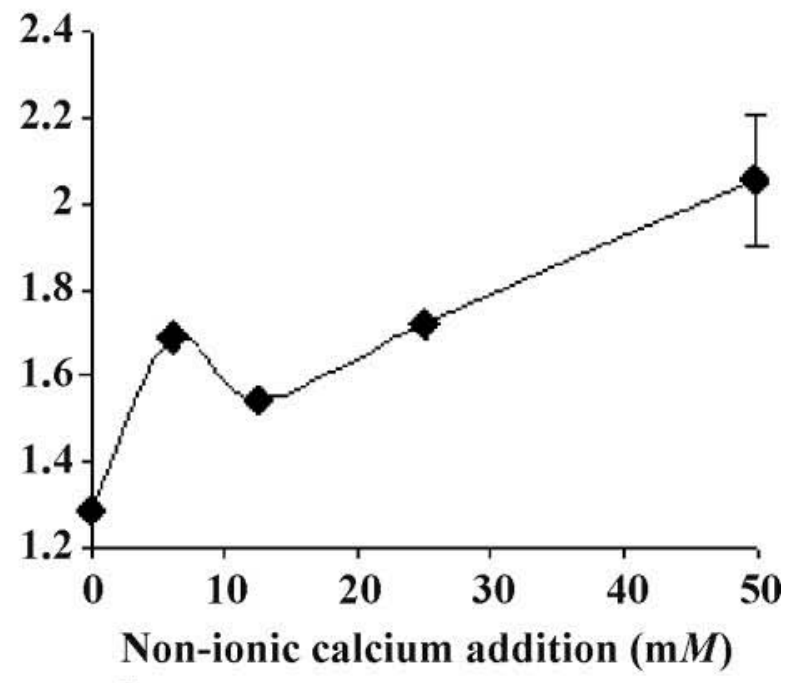

d)

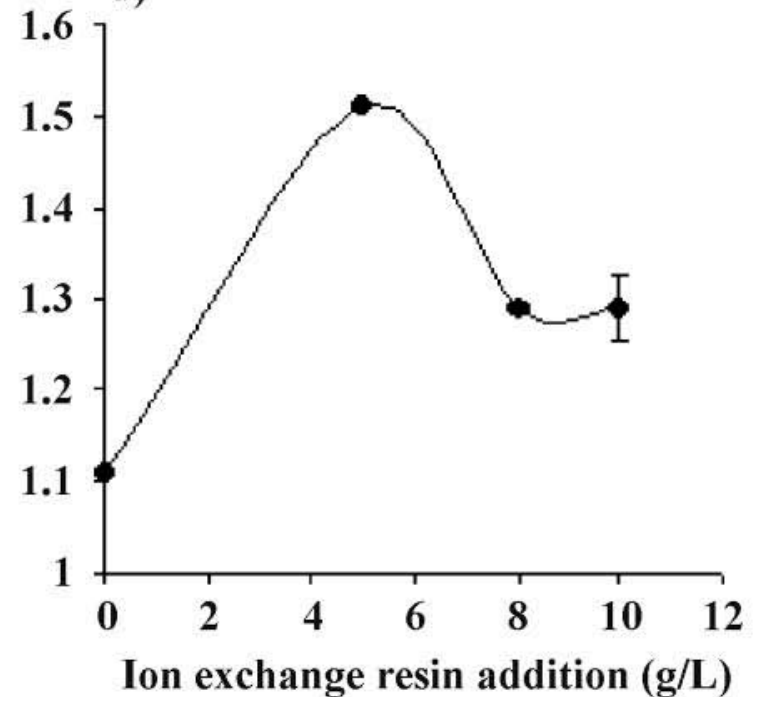

Figure 4. Firmness of yogurt samples as a function of addition of ionic calcium, citrate, non-ionic calcium (Gadocal-K, Gadot Biochemical Industries Ltd., Haifa Bay, Israel), and ion exchange resin (Amberlite IR-120 plus, Sigma-Aldrich Ltd., Castle Hill, Australia): a) ionic calcium and citrate added before heat treatment, b) ionic calcium and citrate added after heat treatment, c) non-ionic calcium added before heat treatment, d) ion exchange resin added before heat treatment of milk. $\boldsymbol{\Lambda}=$ ionic calcium; $\boldsymbol{\|}=$ citrate; $\bullet=$ non-ionic calcium; $\bullet=$ ion exchange resin. Error bars represent pooled standard error. Data points represent averages of 3 experiments. 

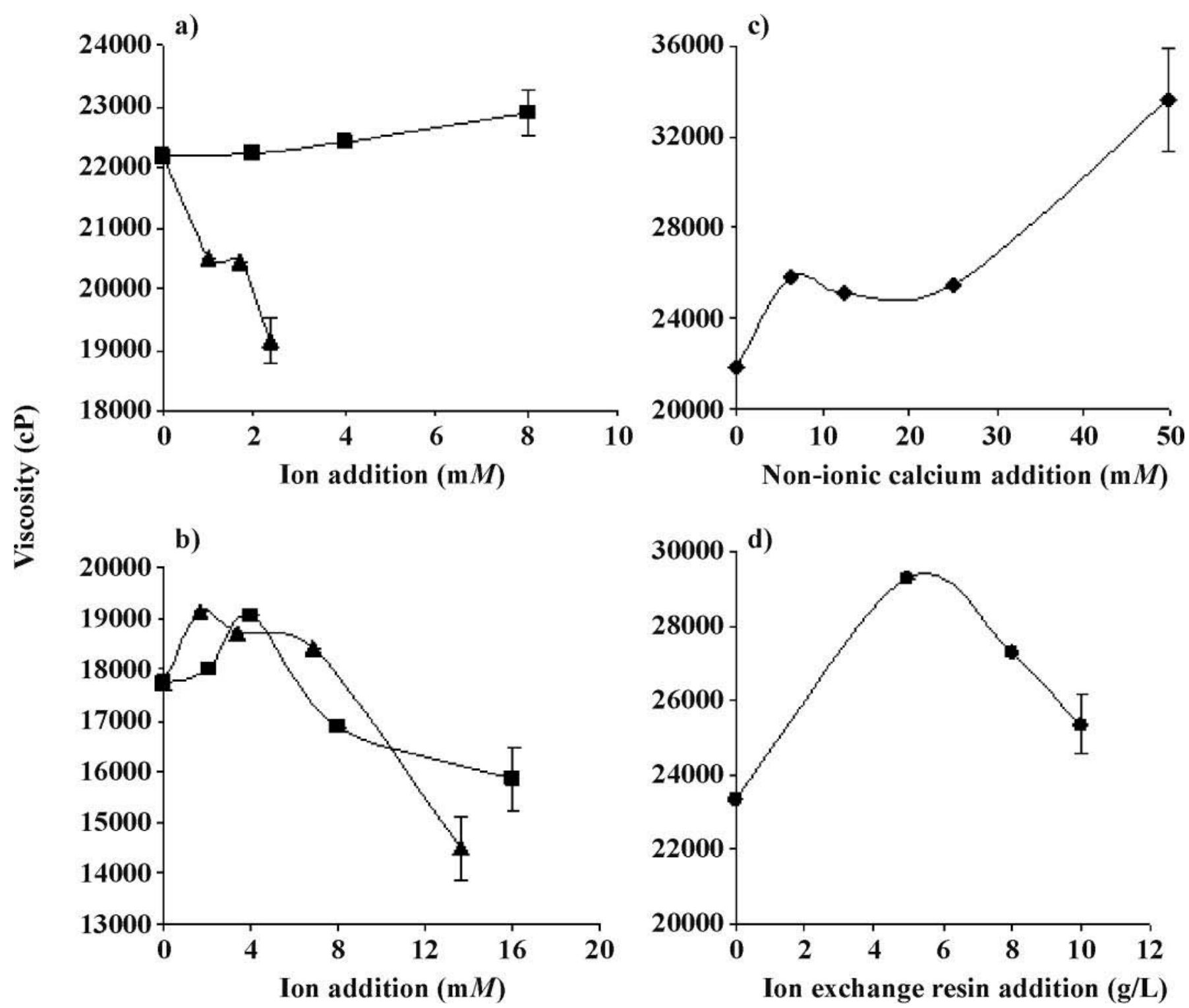

Figure 5. Viscosity of yogurt samples as a function of added ionic calcium, citrate, non-ionic calcium (Gadocal-K, Gadot Biochemical Industries Ltd., Haifa Bay, Israel), and ion exchange resin (Amberlite IR-120 plus, Sigma-Aldrich Ltd., Castle Hill, Australia): a) ionic calcium and citrate added before heat treatment, b) ionic calcium and citrate added after heat treatment, c) non-ionic calcium added before heat treatment, d) ion exchange resin added before heat treatment of milk. $\boldsymbol{\Delta}=$ ionic calcium; $\boldsymbol{\|}=$ citrate; $\boldsymbol{\bullet}$ non-ionic calcium; $\bullet=$ ion exchange resin. Error bars represent pooled standard error. Data points represent averages of 3 experiments.

at heat treatment (results not shown) and is assumed to have augmented the CCP. As a consequence, there was an increase in cross-linking material, gel stiffness, and viscosity; at the same time, $\mathrm{pH}$-induced defects such as susceptibility of whey protein to excessive denaturation during high heat treatment were avoided.

The observations on firmness and viscosity of the stirred probiotic yogurt in this study differ from parallel studies on set yogurts. In stirred yogurt, stirring of the set gel leads to breakdown of the gel network into gel particles, and this breakdown is associated with a natural decrease in firmness compared with that of set yogurts. The physical structure of set yogurts is often evaluated in terms of viscoelastic properties such as gel strength, storage modulus, and loss modulus, whereas it is possible to characterize stirred yogurt only in terms of viscosity and firmness. The other differences between this study and previous studies include the use of a bacterial starter culture rather than glucono$\delta$-lactone for acidification, the presence of gelatin in the formulation, which serves to stabilize the gel network (Fiszman et al., 1999) affecting the resulting firmness 
and viscosity probably in combination with the added salts, and the complexity of the industry-typical milk system compared with simpler systems, such as skim milk, used in similar studies. Furthermore, previous studies involving calcium addition and removal have involved $\mathrm{pH}$ adjustment to 6.7 immediately after ion addition (Goddard and Augustin, 1995; Ozcan-Yilsay et al., 2007); in this study, however, it was important to isolate the effects of calcium and citrate addition on the yogurt properties, and hence, readjustment of $\mathrm{pH}$ was not performed.

\section{CONCLUSIONS}

The study established calcium as a factor that influences the physical properties of stirred yogurt. Both addition and removal of $\mathrm{Ca}^{2+}$ led to increases in the extent of nodulation (i.e., a decrease in smoothness of stirred yogurt) without improving firmness or viscosity. In fact, addition of high concentrations of $\mathrm{Ca}^{2+}$ and removal of large amounts of calcium ions by chelation with citrate resulted in stirred yogurts with decreased viscosity and firmness. The study indicated that the order of addition of calcium and citrate salts (before or after heat treatment) and the nature of calcium added (ionic or nonionic) to the milk influenced the physical properties of stirred yogurt.

Limited calcium removal by means of ion exchange and addition of nonionic calcium in the form of Gadocal-K at high concentration $(49.8 \mathrm{~m} M)$ improved the viscosity and firmness of the stirred yogurt without affecting nodulation. Addition of this level of Gadocal-K corresponds to $\sim 160 \%$ of the normal level of calcium in milk and hence is nutritionally significant. This suggests that addition of Gadocal-K is a possible means of accomplishing calcium fortification of yogurt without significantly adversely affecting its physical attributes and with no changes to the yogurt manufacturing process. The results highlight the fact that studies on smoothness of yogurt should pay attention to the corresponding effects on physical properties such as viscosity and firmness, which cannot be compromised, in an effort to eliminate the occurrence of nodulation.

\section{ACKNOWLEDGMENTS}

We acknowledge the Australian National Food Industry Strategy and Parmalat Australia Ltd., South Brisbane, for providing financial support for this work in the form of a food innovation grant, Parmalat Australia Ltd. for their support and encouragement throughout this study, and Mike Lewis, University of Reading, Berkshire, United Kingdom, for constructive comments on the manuscript.

\section{REFERENCES}

Augustin, M. A., and P. T. Clarke. 1990. Effects of added salts on the heat stability of recombined concentrated milk. J. Dairy Res. 57:213-226.

Canabady-Rochelle, L. S., C. Sanchez, M. Mellema, A. Bot, S. Desobry, and S. Banon. 2007. Influence of calcium salt supplementation on calcium equilibrium in skim milk during $\mathrm{pH}$ cycle. J. Dairy Sci. 90:2155-2162.

Cheng, L. J., P. T. Clarke, and M. A. Augustin. 2002. Seasonal variation in yogurt properties. Aust. J. Dairy Technol. 57:187191.

Cooper, P. J., N. Kipling, and J. F. Gordon. 1974. Observations on the occurrence of nodulation in stirred curd yogurt. XIX Int. Dairy Congr. 1E:733-734.

Davis, J. G. 1973. Yogurt manufacture. Food Manuf. 48:23-73.

Fiszman, S. M., M. A. Lluch, and A. Salvador. 1999. Effect of addition of gelatin on microstructure of acidic milk gels and yogurt and on their rheological properties. Int. Dairy J. 9:895-901.

Fox, P. F., and P. L. H. McSweeney. 1998. Dairy Chemistry and Biochemistry. Blackie Academic \& Professional, London, UK.

Gaucheron, F. 2005. The minerals of milk. Reprod. Nutr. Dev. 45:473-483.

Geerts, J. P., J. J. Bekhof, and J. W. Scherjon. 1983. Determination of calcium ion activities in milk with an ion selective electrode. A linear relationship between the logarithm of time and the recovery of the calcium ion activity after heat treatment. Neth. Milk Dairy J. 37:197-211.

Goddard, S. J., and M. A. Augustin. 1995. Formation of acid-heatinduced skim milk gels in the $\mathrm{pH}$ range 5.0-5.7: Effect of the addition of salts and calcium chelating agents. J. Dairy Res. 62:491-500.

Hansen, P. M. T., and K. Fligner. 1995. Process for the manufacture of a calcium fortified yogurt with improved heat stability. US patent 5449523. Assignee: The Ohio State University Research Foundation, Columbus.

Johnston, D. E., and R. J. Murphy. 1992. Effects of some calciumchelating agents on the physical properties of acid-set milk gels. J. Dairy Res. 59:197-208.

Keogh, M. K., P. M. Kelly, A. M. O’Keeffe, and J. A. Phelan. 1982. Studies of milk composition and its relationship to some processing criteria. II. Seasonal variation in the mineral levels of milk. Int. J. Food Sci. Technol. 6:13-27.

Lee, W. J., and J. A. Lucey. 2006. Impact of gelation conditions and structural breakdown on the physical and sensory properties of stirred yogurts. J. Dairy Sci. 89:2374-2385.

Lin, M. J., M. J. Lewis, and A. S. Grandison. 2006. Measurement of ionic calcium in milk. Int. J. Dairy Technol. 59:192-199.

Lucey, J. A. 2002. Formation and physical properties of milk protein gels. J. Dairy Sci. 85:281-294.

Lucey, J. A., and H. Singh. 1998. Formation and physical properties of acid milk gels: A review. Food Res. Int. 30:529-542.

Martuinez, C. G., M. Becerra, M. Chafer, A. Albors, J. M. Carot, and A. Chiralt. 2002. Influence of substituting milk powder for whey powder on yoghurt quality. Trends Food Sci. Technol. 13:334340.

Ozcan-Yilsay, T., W. J. Lee, D. Horne, and J. A. Lucey. 2007. Effect of trisodium citrate on rheological and physical properties and microstructure of yogurt. J. Dairy Sci. 90:1644-1652.

Philippe, M., F. Gaucheron, Y. Le Graet, F. Michel, and A. Garem. 2003. Physicochemical characterization of calcium supplemented skim milk. Lait 83:45-59.

Ranjith, H. M., M. J. Lewis, and D. Maw. 1999. Production of calcium-reduced milks using an ion-exchange resin. J. Dairy Res. 66:139-144.

Remeuf, F., S. Mohammed, I. Sodini, and J. P. Tissier. 2003. Preliminary observations on the effects of milk fortification and heating on microstructure and physical properties of stirred yogurt. Int. Dairy J. 13:773-782.

Robinson, D. K. 1981. Yogurt manufacture - Some considerations of quality. Dairy Ind. Int. 46:31-33, 35. 
Robinson, D. K. 2003. Yogurt types and manufacture. Pages 10551058 in Encyclopedia of Dairy Sciences. H. Roginski, J. W. Fuquay, P. F. Fox, ed. Academic Press, New York, NY.

Simons, J. W., H. A. Kosters, R. W. Visschers, and H. H. de Jongh. 2002. Role of calcium as trigger in thermal B-lactoglobulin aggregation. Arch. Biochem. Biophys. 406:143-152.

Tamime, A. Y., and H. C. Deeth. 1980. Yogurt: Technology and biochemistry. J. Food Prot. 43:939-977.

Tsioulpas, A., M. J. Lewis, and A. S. Grandison. 2007. Effect of minerals on casein micelle stability of cows' milk. J. Dairy Res. 74:167-173.
Umeda, T., and T. Aoki. 2002. Relation between micelle size and micellar calcium phosphate. Milchwissenschaft 57:131-133.

Vasbinder, A. J., and C. G. de Kruif. 2003. Casein-whey protein interactions in heated milk: The influence of $\mathrm{pH}$. Int. Dairy J. 13:669-677.

Walstra, P., and R. Jenness. 1984. Dairy Chemistry and Physics. Wiley Intersciences, New York, NY.

White, J. C. D., and D. T. Davies. 1958. The relation between the chemical composition of milk and the stability of the caseinate complex. J. Dairy Res. 25:236-255. 